\title{
TÉCNICAS PARA AVALIAÇÃO IN VITRO DO EFEITO DE HERBICIDAS SOBRE BACILLUS THURINGIENSIS BERLINER VAR. KURSTAKI*
}

\author{
E.R.L. Silva ${ }^{1 *}$, L.F.A. Alves ${ }^{2 * * *}$, J. Santos ${ }^{1}$, M. Potrich $^{1 * *}$, L. Sene ${ }^{3}$ \\ ${ }^{1}$ Universidade Estadual de Londrina, Centro de Ciências Agrárias, Laboratório de Entomologia, Rod. Celso \\ Garcia Cid, Pr 445, km 380, CEP 86051-990, Londrina, PR, Brasil. E-mail: evertonloz@gmail.com
}

\section{RESUMO}

\begin{abstract}
Objetivou-se comparar técnicas para a avaliação in vitro do efeito de herbicidas sobre Bacillus thuringiensis Berliner var. kurstaki (Btk). Foram testados os herbicidas sulfentrazone, lactofen, imazethapyr, fenoxaprope metribuzin em duas concentrações, sobre células eesporos, em meioágar nutriente sólido (MS) e caldo nutriente (CN) - líquido (ML), além da metabolização (MT) de tais produtos por Btk. Para células em MS, os herbicidas foram testados incorporados ao meio eem discos de papel-filtro impregnados nos produtos. Avaliou-se, respectivamente, as unidades formadoras de colônia por mililitro (UFC/mL) e a formação de halo de inibição. Para células, a mistura Btk + produtos $+\mathrm{CN}$ foi incubada em frascos erlemmeyer $\left(30 \pm 2^{\circ} \mathrm{C}, 150 \mathrm{rpm}, 24 \mathrm{~h}\right) \mathrm{e}$, em seguida, a mistura foi diluída e inoculada em MS, avaliando-se o número de UFC $/ \mathrm{mL}$. Os testes de MT e esporos foram realizados em líquido (água para MT e CN para esporos). O efeito dos produtos variou conforme a concentração utilizada, técnica de avaliação e a fase/estágio do microrganismo, sendo a técnica de avaliação em ML a mais indicada para a avaliação do efeito dos herbicidas sobre células de Btk, pois não apresenta limitações para difusão e permite quantificação. Os herbicidas, independentemente da concentração, foram incompatíveis para a célula, porém sulfetrazone e imazethapyr foram metabolizados por Btk. Todos herbicidas foram compatíveis com esporos, possibilitando a germinação, porém a concentração e tempo influenciaram nos resultados.
\end{abstract}

PALAVRAS-CHAVE: Bactéria entomopatogênica, seletividade, compatibilidade.

\section{ABSTRACT}

TECHNIQUESFOR EVALUATIONOFTHE IN-VITROEFFECTOF HERBICIDESONBACILLUS THURINGIENSIS BERLINER VAR. KURSTAKI. The objective of this research was to compare techniques for the in-vitro evaluation of the effect of herbicides on Bacillus thuringiensis Berlinervar. kurstaki (Btk). The herbicides sulfentrazone, lactofen, imazethapyr, fenoxaprop and metribuzin were tested at two concentrations, on cells and spores, in nutrient agar (NA) solid medium (SM), and in nutrient broth (NB) liquid medium (LM), in addition to their metabolization (MT) by Btk. For cells, the fungicides in NA were tested incorporated into the medium and on filter-paper disks impregnated with the products. Evaluation was made, respectively, of the number of colony-unit formers per milliliter CFU.mL $\mathrm{mL}^{-1}$ and of the formation of an inhibition halo. For cells, the Btk + products $+\mathrm{NB}$ mixture was incubated in Erlenmeyer flasks $\left(30 \pm 2^{\circ} \mathrm{C}, 150 \mathrm{rpm}, 24 \mathrm{~h}\right)$ and then the NB was diluted and inoculated onto NA, followed by evaluation of the number of CFU.mL ${ }^{-1}$. The MT and spore tests were performed in liquid medium (water for MT and NB for spores). The effects of the products varied with their concentration, the evaluation technique used and the developmental stage of the microorganism. The LM evaluation technique proved to be the best for evaluating the effect of herbicides on Btk cells, as it did not show any diffusion limitations and it also allowed for quantification. The herbicides, regardless of their concentration, were incompatible with the cells, although sulfetrazone and imazethapyr were metabolized by Btk. All herbicides were compatible with the spores, allowing for germination, but the concentration and time influenced the results.

KEY WORDS: Entomopathogenic bacteria, selectivity, compatibility.

\footnotetext{
${ }^{2}$ Universidade Estadual do Oeste do Paraná, Centro de Ciências Biológicas e da Saúde, Cascavel, PR, Brasil.

${ }^{3}$ Universidade Estadual do Oeste do Paraná, Centro de Ciências Médicas e Farmacêuticas, Cascavel, PR, Brasil.

*Parte da dissertação do primeiro autor desenvolvida para obtenção do título de Mestre em Agronomia pela Universidade Estadual do Oeste do Paraná, Mal. Cândido Rondon, PR, Brasil.

**Programa de Pós-graduação em Agronomia, Nível Doutorado.

***Bolsista de Produtividade Científica - CNPq.
} 


\section{INTRODUÇÃO}

Bacillus thuringiensis Berliner (Bt) é utilizado há mais de 50 anos para o controle de pragas agrícolas e insetos vetores de doenças. Atualmente, éo ingrediente ativo mais utilizadocomercialmentenos bioinseticidas, com um mercado atual variando de $80 \%$ (MorAEs et al., 1998) até 90 a 95\% (VALADARES-Inglis etal., 1998), representandocerca de $1 \%$ destemercadona década de 1990 (Moraes etal., 1998). No Brasil, B. thuringiensis Berliner var. kurstaki (Btk) é utilizado em cerca de 150.000 ha para o controle de cerca de 30 pragas nas diversas culturas (PoLANCZYK, 2004).

A utilização de produtos fitossanitários seletivos aos agentes de controle biológico pode ser uma das estratégias mais seguras e eficientes, principalmente nas culturas onde a utilização de tais produtos seja indispensável, como as frutíferas de clima temperado, citros, café, algodão, soja, dentre outras (Alves et al., 1998).

A referida estratégia contribui para a conservação de populações de inimigos naturais, potencializando o controle biológico. Também pode reduzir o uso de produtos fitossanitários, custos ao produtor e contaminação ambiental. ConformeSosa-Gómez;MosCARDI (2003), no caso dos entomopatógenos, o efeito dos produtos pode estimular, inibir ou não alterar o modo de ação destes.

São várias as técnicas utilizadas para a avaliação do efeito de produtos fitossanitários sobre bactérias. Neste sentido, Dougherty et al. (1971) e Jimenez et al. (1989) avaliaram os efeitos de produtos fitossanitários sobre esporos de B. thutingiensis var. thuringiensis (Btt) por meio da técnica de discos de papel impregnados nas caldas dos produtos. Por sua vez, SutTer et al. (1971) estudaram os efeitos de inseticidas sobre células de Btt em meio de cultura líquido. Posteriormente, CHEn et al. (1974) testaram duas formulações de Bt e diferentes concentrações de inseticidas. Ainda, por meio da técnica de mistura dos produtos ao meio de cultura fundido, SALERNo et al. (1999) avaliaram o efeito de herbicidas, fungicidas e inseticidas sobre 16 cepas de Bt, assim como também Batista Filho et al. (2001) testaram o efeito de inseticidas sobre Bt.

Estudos sobre o efeito de produtos fitossanitários em Bt são necessários, uma vez que são escassos, em geral desatualizados, sendo a maioria realizados com inseticidas. Além disso, apresentam variação na metodologia, cuja falta de padronização pode comprometer os resultados.

Em trabalho recente, Silva et al. (2006) avaliaram o efeito de fungicidas sobre células e esporos de Btk por meio de diferentes técnicas e constataram que o efeito variou conforme a técnica, a concentração dos produtos, tempo de contato e fase/estágio de desenvolvimento do patógeno.

Nesse sentido, este trabalho tem por objetivo testar e comparar diferentes técnicas para a avaliação do efeito deherbicidas sobrecélulas eesporos deBtk, bem como verificar a capacidade de metabolização da célula.

\section{MATERIAL E MÉTODOS}

Os experimentos foram conduzidos no Laboratório de Zoologia de Invertebrados (CCBS) e nos Laboratórios de Bioquímica e Controle Microbiológico de Água, Alimentose Medicamentos(CCMF) da Unioeste, Campus de Cascavel.

Foram testados herbicidas na concentração recomendada pelo fabricante (CR) e na metade desta $(1 / 2 \mathrm{CR})$, sendo cada uma considerada um tratamento, sobre células e esporos de Bacillus thuringiensis var. kurstaki (Btk) isolado do produto comercial Dipel $\mathrm{PM}^{\circledR}$ (Tabela 1). Os meios de cultura utilizados foram ágar nutriente-sólido(MS) ecaldo nutriente-líquido(ML), sendo também verificada a capacidade do Btk em metabolizar (MT) os produtos, bem como o efeito dos referidos produtos sobre esporos em ML. As células foram quantificadas por absorbância em espectrofotômetro $(600 \mathrm{~nm})$ e correlação em curva padrão, a partir de um pré-cultivo de amostra pura em caldo nutriente $(\mathrm{CN})\left(30 \pm 2^{\circ} \mathrm{C}, 150 \mathrm{rpm}, 24 \mathrm{~h}\right)$.

Tabela 1 - Dados dos herbicidas utilizados nos experimentos.

\begin{tabular}{llllc}
\hline \multicolumn{2}{c}{ Produto } & Formulação & Grupo químico & ConcentraçãorecomendadaL/ha ${ }^{1}$ \\
\cline { 1 - 2 } Técnico & Nome comercial & & & \\
\hline Sulfentrazone & Boral & SC & Aril triazolinona & 1,2 \\
Lactofen & Cobra & CE & Difenil éter & 0,5 \\
Imazethapyr & Pivot & SL & Imidazolinona & 1,0 \\
Fenoxaprop & Podium & CE & Ácido Fenoxicarboxílico & 1,0 \\
Metribuzin & Sencor & SC & Triazinona & 1,0 \\
\hline
\end{tabular}

${ }^{1}$ Diluição padronizada em 200 L água/ha.

SC = Suspensão Concentrada; $\mathrm{CE}=$ Concentração Emulsionável; SL = Líquido Solúvel. 
Efeito dos produtos sobre células vegetativas em meio de cultura sólido - Produtos misturados ao meio de cultura

Os herbicidas foram adicionados e misturados em meio ágar nutriente $(\mathrm{AN})$ fundido $\left(45-50^{\circ} \mathrm{C}\right)$, ainda não solidificado e, em seguida, a mistura transferida para placasde Petri. Considerando que o produto podeinibir, ser indiferente ou estimular o crescimento bacteriano, após a solidificação, para cada concentração de produto foram inoculadas suspensões de células do pré-cultivo, nas concentrações $1,7 \times 10^{2}, 1,7 \times$ $10^{3}$ e $1,7 \times 10^{4}$ unidades formadoras de colônia por mililitro (UFC/mL), sendo, posteriormente, avaliada a suspensão na concentração mais adequada, de acordo com a metodologia desenvolvida por E. M. Rios (UFPE) (Alves; MorAEs, 1998). Foram utilizadas duas placas de Petri por suspensão, sendo que cada uma recebeu cinco gotas de cinco microlitros em pontos eqüidistantes. A pós incubação $\left(30 \pm 2^{\circ} \mathrm{C}, 20 \mathrm{~h}\right)$ foram quantificadas as UFC/ $\mathrm{mL}$, e classificado como compatível com a célula de Btk o produto que permitiu crescimento significativamente igual ou superior ao da testemunha, e incompatível o que não permitiu o crescimento bacteriano ou foi significativamente menor que o da testemunha.

\section{Contato com discos de papel de filtro impregna- dos com os produtos}

As caldas foram preparadas em frascos com capacidade de $100 \mathrm{~mL}$ contendo $50 \mathrm{~mL}$ de água destilada estéril, adicionado dos herbicidas. Em seguida, discos de papel de filtro de um centímetro de diâmetro foram mergulhados nas caldas e colocados em contato com a superfície do meio decultura ANjáinoculado com 100 microlitros do pré-cultivo de Btk $\left(1,2 \times 10^{6}\right.$ $\mathrm{UFC} / \mathrm{mL}$ ) distribuído na superfície do meio com alça de Drigalsky. Foram utilizadas duas placas com cinco discos para cada tratamento e, após incubação (30 $\pm 2^{\circ} \mathrm{C}, 24 \mathrm{~h}$ ), avaliou-se a formação de um halo no crescimento das colônias ao redor dos discos, sendo que a presença e ou ausência do mesmo indicou, respectivamente, a incompatibilidade e compatibilidade. No caso da presença de halo com a presença de UFC, o produto foi classificado como parcialmente compatível ou parcialmente incompatível.

Efeito dos produtos sobre células vegetativas em meio de cultura líquido

Foram utilizados frascos erlenmeyer com capacidade de $250 \mathrm{~mL}$ contendo $50 \mathrm{~mL}$ de $\mathrm{CN}$ adicionado dos herbicidas e de 0,5 mililitros $\left(1 \times 10^{7} \mathrm{UFC} / \mathrm{mL}\right)$ da suspensão do pré-cultivo de Btk. As misturas (tratamentos) foram incubadas em agitador horizontal (30 $\left.\pm 2^{\circ} \mathrm{C}, 150 \mathrm{rpm}, 24 \mathrm{~h}\right)$ e, em seguida, submetidos ao método de diluições seriadas $\left(10^{-3}, 10^{-4}\right.$ e $\left.10^{-5}\right)$, considerando-se a possibilidade de variação no comportamento da bactéria, como explicado no item anterior. A partir de cada suspensão, foi inoculada, em pontos eqüidistantes, cinco gotas de cinco microlitros em duas placas de Petri com AN. Após incubação (30 \pm $\left.2^{\circ} \mathrm{C}, 20 \mathrm{~h}\right)$ foi avaliado o crescimento vegetativo, quantificando-se o número das UFC/mL por ponto.

\section{Capacidade de metabolização dos produtos por Btk}

Para este teste foram seguidos todos os procedimentos e condições utilizados na técnica em ML, sendo o meio de cultura substituído por água destilada estéril. Em cada mistura (tratamento) foi inoculado 0,5 mL $\left(7 \times 10^{6} \mathrm{UFC} / \mathrm{mL}\right)$ do pré-cultivo de Btk, e previamente à adição da suspensão de Btk nas misturas herbicidas + água, e ao final do período de 24 h de incubação em agitador horizontal, mediu-se o pH em cada frasco para verificação de uma possível variação deste no caso de metabolização.

\section{Efeito dos herbicidas sobre a germinação de Btk em meio líquido}

Foram utilizados frascos erlenmeyer com capacidade de $250 \mathrm{~mL}$ contendo $50 \mathrm{~mL}$ de água destilada estéril, adicionado dos herbicidas e de $0,5 \mathrm{~mL}\left(10^{6}\right.$ $\mathrm{UFC} / \mathrm{mL}$ ) de uma suspensão preparada a partir do produto comercial Dipel PM ${ }^{\circledR}$. Os frascos foram incubados em agitador horizontal $\left(30 \pm 2^{\circ} \mathrm{C}, 150 \mathrm{rpm}, 2 \mathrm{~h}\right)$, sendo realizadas coletas de alíquotas de um $\mathrm{mL}$ de cada frasco, nos intervalos de tempos de uma e duas horas. Após cada coleta, procedeu-se uma diluição decimal e a transferência para placas de Petri com meio AN. Todos os procedimentos e condições para a inoculaçãoe incubação foram os mesmos utilizados na técnica em ML. Avaliou-se a germinação dos esporos, nos respectivos intervalos de tempos, quantificando-se as UFC/mL. Foi classificado como compatível com o esporo de Btk, o produto que permitiu germinação e crescimento, significativamente igual ou superior ao da testemunha, e incompatível, quando não houve a germinação ou esta foi significativamente inferior a da testemunha.

Em todas as técnicas, a testemunha constou do tratamento sem os herbicidas.

\section{Análise Estatística}

Os experimentos foram realizados segundo delineamento experimental inteiramente casualizado. Exceto para a técnica dos discos impregnados, cada ponto com suspensão de Btk nas placas foi conside- 
rado como repetição. Os dados foram submetidos à análise de variância pelo teste $\mathrm{F}$ e as médias comparadas entre si pelo teste de Tukey, ambos com 5\% de significância. Para o teste com esporos foi utilizada a análise de parcelas subdivididas no tempo (Split Plot), sendo as médias comparadas entre si pelo teste de Tukey a 5\% de significância. Quando necessário, os dados foram previamente transformados por $\mathrm{x}+1$. $\sqrt{x+1}$. Para todas as análises utilizou-se o programa estatístico SISVAR (FERREIRA, 2005).

\section{RESULTADOS E DISCUSSÃO}

Efeito dos produtos sobre células vegetativas em meio de cultura sólido - Produtos misturados ao meio de cultura

Verificou-se que, independente da concentração utilizada, o efeito dos herbicidas foi negativo, uma vez que nenhum possibilitou a formação de UFC/ mL de Btk, sendo todos classificados como incompatíveis. Em trabalho com fungicidas, utilizando-se de técnica semelhante, SILva et al. (2006) verificaram que para epoxiconazole, tebuconazole, azoxystrobin e fentin hidróxido, independentemente da concentração utilizada, não houve formação de UFC/mL. Apenas carbendazin $1 / 2$ CR permitiu a formação de $\mathrm{UFC} / \mathrm{mL}$, não diferindo estatisticamente da testemunha. Da mesma forma, SALERNo et al. (1999) testaram cinco herbicidas, três fungicidas e dois inseticidas sobre 16 cepas de Bt, e verificaram que o efeito dos produtos sobre a bactéria variou conforme o produto e a concentração utilizada, não havendo diferença entre as cepas dentro de uma mesma concentração. No caso, os herbicidas bentazon e imazaquin, na CR, permitiram a formação UFC/mL, não diferindo estatisticamente da testemunha. Os demais herbicidas, propaquizafop, cletodim e fenoxaprop-p-etil permitiram a formação de UFC numa concentração mais baixa.

Em trabalho com inseticidas, BATISTA FILHO et al. (2001) observaram que o efeito destes sobre Bt variou de acordo o produto e as concentrações utilizadas, sendo que na concentração máxima recomendada, endosulfan, monocrotofos e deltametrina não permitiram a germinação do $\mathrm{Bt}$, ao passo que para tiametoxan, carbosulfan, diafentiuron, imidaclopride, acefato e fipronil a média de germinação foi significativamente igual a da testemunha. Por sua vez, para a concentração mínima recomendada não verificaram efeito negativo sobre Bt, sendo que a média de germinação sob o efeito de diafentiuron foi significativamente superior a testemunha, e para os demais produtos a média foi significativamente igual a da testemunha.

\section{Contato com discos de papel de filtro impregna- dos com os produtos}

Observou-se que o efeito dos herbicidas sobre as células de Btk variou conforme a concentração utilizada dos produtos, pois, exceto para o metribuzin, nos tratamentos com $1 / 2 \mathrm{CR}$, na maioria dos discos não houve formação de halo.

Diferentemente do observado na técnica anterior, nenhum herbicida foi totalmente incompatível com Btk, sendo que sulfentrazone e imazethapyr, na CR, apresentaram seis discos com formação de halo com presença de UFC.

No caso de metribuzin e imazethapyr, na $1 / 2 \mathrm{CR}$, e lactofen, na CR, cinco discos não apresentaram halo de inibição, sendo que os demais apresentaram halo com presença de UFC. Resultado semelhante foi verificado para sulfentrazoneelactofen, na $1 / 2 \mathrm{CR}$, efenoxaprop, na $\mathrm{CR}$, pois em quatro discos houve formação de halo com presença de UFC. Por sua vez, fenoxaprop, na $1 / 2 \mathrm{CR}$, e metribuzin, na $\mathrm{CR}$, apresentaram, respectivamente, apenas doise três discoscomformação dehalocomUFC, sendo classificados como compatíveis ao Btk. A presença de halo de inibição pode ser justificada devido à seleção de colônias resistentes e/ou a distribuição irregular do produto no meio decultura, como será discutido posteriormente. Vale ressaltar que variação semelhante quanto à formação de halo com UFC foi observado em testes com fungicidas por SILVA et al. (2006).

JiMENEZ et al. (1989) também observaram variação do halo conforme a categoria do produto testado e a concentração utilizada. Segundo os autores, os tratamentos com a $1 / 2$ da CR foram compatíveis com Bt. Da mesma forma, em teste semelhante com inseticidas e herbicidas, DOUGHERTY et al. (1971) verificaram diferentes respostas de inibição, com a formação de halo maior que um milímetro, com cerca de um milímetro e a nãoformação dehalo. Porém, ambos os autores não relatam a formação de halo com a presença de UFC.

Efeito dos produtos sobre células vegetativas em meio de cultura líquido

Nenhum herbicida apresentou média de UFC/ $\mathrm{mL}$ significativamente superior à testemunha, sendo sulfentrazone o único com formação de UFC/mL, porém, com respectiva redução de $60,3 \%$ e $77,9 \%$ para a 1/2 CR e CR, em relação à testemunha (Tabela 2). Valores superiores à testemunha foram verificados em testes semelhantes com fungicidas. $\mathrm{O}$ produto epoxiconazole, na $1 / 2 \mathrm{CR}$, estimulou o desenvolvimento de Btk, com média de UFC/mL significativamente superior aos demais tratamentos. Além disso, azoxystrobin, na $1 / 2 \mathrm{CR}$, e epoxiconazole na CR apresentaram médias de UFC/mL significativamente iguais à testemunha SiLvA et al. (2006). 
Tabela 2 - Média de UFC/mL ( \pm EP) a partir de células de B. thuringiensis Berliner var. kurstaki após incubação em caldo nutriente $\left(30 \pm 2^{\circ} \mathrm{C}\right.$ e $\left.150 \mathrm{rpm}, 24 \mathrm{~h}\right)$ com herbicidas em diferentes concentrações.

\begin{tabular}{llccc}
\hline Tratamentos & Concentração $^{1}$ & $\begin{array}{c}\text { Média UFC/mL } \\
\left(\times 10^{5}\right)\end{array}$ & \% Relação à testemunha ${ }^{2}$ & $\begin{array}{c}\text { Diferença em relação ao } \\
\text { inóculoinicial }^{3}\left(\times 10^{5}\right) \text { UFC } / \mathrm{mL}^{-}\end{array}$ \\
\hline Testemunha & - & $272 \pm 1,25 \mathrm{a}$ & - & +270 \\
Sulfentrazone & $0,6(1 / 2 \mathrm{R})$ & $108 \pm 0,48 \mathrm{~b}$ & $-60,3$ & +106 \\
Sulfentrazone & $1,2(\mathrm{R})$ & $60 \pm 0,38 \mathrm{c}$ & $-77,9$ & $=$ \\
Fenoxaprop & $1,0(\mathrm{R})$ & $0,0 \mathrm{~d}$ & $=$ & $=$ \\
Fenoxaprop & $0,5(1 / 2 \mathrm{R})$ & $0,0 \mathrm{~d}$ & $=$ & $=$ \\
Lactofen & $0,5(\mathrm{R})$ & $0,0 \mathrm{~d}$ & $=$ & $=$ \\
Lactofen & $0,25(1 / 2 \mathrm{R})$ & $0,0 \mathrm{~d}$ & $=$ & $=$ \\
Metribuzin & $1,0(\mathrm{R})$ & $0,0 \mathrm{~d}$ & $=$ & $=$ \\
Metribuzin & $0,5(1 / 2 \mathrm{R})$ & $0,0 \mathrm{~d}$ & $=$ & $=$ \\
Imazethapyr & $1,0(\mathrm{R})$ & $0,0 \mathrm{~d}$ & $=$ & \\
Imazethapyr & $0,5(1 / 2 \mathrm{R})$ & $0,0 \mathrm{~d}$ & & $=$ \\
\hline CV $(\%)$ & & 11,35 & & $=$ \\
\hline
\end{tabular}

Médias seguidas pela mesma letra minúscula na coluna não diferem significativamente entre si pelo teste de Tukey $(\alpha=5 \%)$.

= Cálculo não realizado por não haver formação de Unidade Formadora de Colônia (UFC)

${ }^{1}$ Concentração dos produtos: $\mathrm{R}=$ recomendada, $1 / 2 \mathrm{R}=$ metade da recomendada.

2\% Relação à testemunha: [(Média de UFC/mL do tratamento/ Média de UFC/mL da testemunha × 100 ) - 100], sendo os valores positivos para aumento de UFC e negativos para a redução em relação à testemunha.

${ }^{3}$ Diferença com relação ao inóculo inicial = [(Concentração inicial de inóculo (UFC/mL) nos frascos erlenmeyer) (Concentração celular (UFC/mL) após 24h)], sendo os valores positivos para aumento de UFC/mL e negativos para redução.

Quando as médias de UFC/mL são comparadas à concentração do inóculo adicionada inicialmente nos frascos, verifica-se crescimento bacteriano(Tabela 2). Tal fato evidencia, assim como na técnica de discos impregnados, uma possível seleção de população resistente, pois a população inoculada se manteve e cresceu, ainda que em quantidade menor que a testemunha.

Sutter et al. (1971), trabalhando com Btt, verificaram que a bactéria se comportou de forma diferentena presença e ausência de determinados inseticidas, e em relação às concentrações utilizadas. Além disso, observaram inibição da multiplicação bacteriana por alguns inseticidas e a compatibilidade, sem inibição, com outros.Segundo os autores, a resistência podeser atribuída à capacidade de alguns indivíduos da população do microrganismo em metabolizar o produto. Da mesma forma, MoRRIS (1975) observou variação conforme as concentrações e o produto utilizado.

\section{Capacidade de metabolização dos produtos por Btk}

A capacidade de metabolização variou conforme o produto e a concentração utilizada, sendo que sulfentrazone e imazethapyr, na $1 / 2 \mathrm{CR}$, apresentaram médias de UFC $/ \mathrm{mL}$ superiores à testemunha. Porém, somente sulfentrazone, na CR, obteve média deUFC/
$\mathrm{mL}$ significativamente superior à testemunha, com crescimento de $129,4 \%$. Nos demais tratamentos houve redução das médias de UFC/mL, variando de $17,6 \%$ a $88,2 \%$ (Tabela 3). A capacidade de metabolização provavelmente está relacionada ao grupo químico e/ou aos componentes dos produtos, pois, em trabalho com fungicidas, Silva et al. (2006) observaram que não houve diferença significativa entre os tratamentos.

Fenoxaprop, na $\mathrm{CR}$, foi o único que reduziu as $\mathrm{UFC} / \mathrm{mL}$, sendo que nos demais tratamentos houve crescimento bacteriano, variando de $2 \times 10^{4}$ a $64 \times 10^{4}$ $\mathrm{UFC} / \mathrm{mL}$. Além disso, lactofenefenoxaprop, emambas as concentrações, apresentaram menor valor inicial de $\mathrm{pH}$ (variando entre 4,57 e 5,77) e permitiram menor crescimento bacteriano tanto em relação ao inóculo inicial como à testemunha, podendo atribuir a este fator uma provável causa para inibição do desenvolvimento bacteriano (Tabela 3).

Vale ressaltar que o $\mathrm{pH}$ em torno de 7,2 a 7,6 é o mais adequado no início da fermentação, pois durante o processo, devido à formação de ácidos orgânicos, há uma redução deste, a qual pode interferir no crescimento bacteriano (MorAEs et al., 1998).

Efeito dos herbicidas sobre a germinação de Btk em meio líquido 
Tabela 3 - Médias de UFC/mL ( \pm EP) a partir de células B. thuringiensis Berliner var. kurstaki após incubação $\left(30 \pm 2^{\circ} \mathrm{C}\right.$ e $150 \mathrm{rpm}, 24 \mathrm{~h}$ ) com água e herbicidas em diferentes concentrações e $\mathrm{pH}$ inicial e final.

\begin{tabular}{|c|c|c|c|c|c|c|}
\hline \multirow[t]{2}{*}{ Tratamento } & \multirow[t]{2}{*}{ Concentração ${ }^{1}$} & \multirow[t]{2}{*}{ Média UFC/mL $\left(\times 10^{4}\right)$} & \multirow{2}{*}{$\begin{array}{l}\text { \% Relação à } \\
\text { testemunha }{ }^{2}\end{array}$} & \multirow{2}{*}{$\begin{array}{c}\text { Diferença em relação } \\
\text { ao inóculo inicial }{ }^{3} \\
\left(\times 10^{4}\right) \mathrm{UFC} / \mathrm{mL}\end{array}$} & \multicolumn{2}{|c|}{$\mathrm{pH}$} \\
\hline & & & & & $0 \mathrm{~h}$ & $24 \mathrm{~h}$ \\
\hline Testemunha & - & $34 \pm 0,56 \mathrm{bcd}$ & - & +20 & 6,65 & 7,50 \\
\hline Sulfentrazone & $1,2(\mathrm{R})$ & $78 \pm 0,50 \mathrm{a}$ & $+129,4$ & +64 & 7,81 & 7,25 \\
\hline Sulfentrazone & $0,6(1 / 2 R)$ & $62 \pm 0,48 \mathrm{ab}$ & $+82,3$ & +48 & 7,53 & 7,70 \\
\hline Imazethapyr & $0,5(1 / 2 \mathrm{R})$ & $42 \pm 0,50 \mathrm{abc}$ & $+23,5$ & +28 & 6,45 & 7,52 \\
\hline Metribuzin & $1,0(\mathrm{R})$ & $28 \pm 0,60 \mathrm{bcd}$ & $-17,6$ & +14 & 6,90 & 7,68 \\
\hline Imazethapyr & $0,25(\mathrm{R})$ & $22 \pm 0,43 \mathrm{~cd}$ & $-35,3$ & +8 & 6,60 & 7,55 \\
\hline Metribuzin & $0,5(1 / 2 \mathrm{R})$ & $22 \pm 0,38 \mathrm{~cd}$ & $-35,3$ & +8 & 6,66 & 7,66 \\
\hline Lactofen & $0,251 / 2 \mathrm{R}$ & $18 \pm 0,23 \mathrm{~cd}$ & $-47,0$ & +4 & 4,78 & 7,16 \\
\hline Fenoxaprop & $0,5(1 / 2 R)$ & $16 \pm 0,25 \mathrm{~cd}$ & $-52,9$ & +2 & 5,77 & 6,20 \\
\hline Lactofen & $0,5(\mathrm{R})$ & $16 \pm 0,20 \mathrm{~cd}$ & $-52,9$ & +2 & 4,57 & 6,50 \\
\hline Fenoxaprop & $1,0(\mathrm{R})$ & $2 \pm 0,13 d$ & $-88,2$ & -12 & 5,65 & 7,52 \\
\hline
\end{tabular}

Médias seguidas pela mesma letra minúscula na coluna não diferem significativamente entre si pelo teste de Tukey $(\alpha=5 \%)$.

${ }^{1}$ Concentração dos produtos: $\mathrm{R}=$ recomendada, $1 / 2 \mathrm{R}=$ metade da recomendada.

2\% Relação à testemunha: [(Média de UFC/mL do tratamento/ Média de UFC/mL da testemunha × 100 ) - 100], sendo os valores positivos para aumento de UFC e negativos para a redução em relação à testemunha.

${ }^{3}$ Diferença com relação ao inóculo inicial $=[$ (Concentração inicial de inóculo $(\mathrm{UFC} / \mathrm{mL})$ nos frascos erlenmeyer $)-$ (Concentração celular (UFC/mL) após 24h )], sendo os valores positivos para aumento de UFC/mL e negativos para redução.

Tabela 4 - Média de UFC/mL ( \pm EP) de B. thuringiensis Berliner var. kurstaki com 1 e 2 horas de incubação $\left(30 \pm 2^{\circ} \mathrm{C}\right.$ e $150 \mathrm{rpm})$ com água e herbicidas em diferentes concentrações.

\begin{tabular}{|c|c|c|c|c|c|}
\hline \multirow[t]{2}{*}{ Tratamento } & \multirow[t]{2}{*}{ Concentração $^{1}$} & \multicolumn{2}{|c|}{ Germinação (1h) } & \multicolumn{2}{|c|}{ Germinação (2h) } \\
\hline & & $\mathrm{UFC} / \mathrm{mL}\left(\times 10^{5}\right)$ & $\begin{array}{c}\text { Relação à } \\
\text { testemunha }{ }^{2}\end{array}$ & $\mathrm{UFC} / \mathrm{mL}\left(\times 10^{5}\right)$ & $\begin{array}{c}\text { Relação à } \\
\text { Testemunha² }\end{array}$ \\
\hline Testemunha & - & $618 \pm 0,51$ Abcd & - & $676 \pm 1,06 \mathrm{Aab}$ & - \\
\hline Fenoxaprop & $\mathrm{R}$ & $742 \pm 1,27 \mathrm{Aa}$ & $+20,06$ & $634 \pm 0,42 \mathrm{Bb}$ & $-6,21$ \\
\hline Lactofen & $\mathrm{R}$ & $708 \pm 0,84 \mathrm{Aab}$ & $+14,56$ & $628 \pm 0,43 \mathrm{Bb}$ & $-7,10$ \\
\hline Metribuzin & $\mathrm{R}$ & $688 \pm 2,36 \mathrm{Aab}$ & $+11,33$ & $738 \pm 1,32 \mathrm{Aa}$ & $+9,17$ \\
\hline Sulfentrazone & $\mathrm{R}$ & $682 \pm 1,01 \mathrm{Aab}$ & $+10,36$ & $634 \pm 1,29 \mathrm{Ab}$ & $-6,21$ \\
\hline Imazethapyr & $\mathrm{R}$ & $662 \pm 1,50 \mathrm{Aab}$ & $+7,12$ & $642 \pm 0,74 \mathrm{Aab}$ & $-5,03$ \\
\hline Lactofen & $1 / 2 R$ & $640 \pm 1,38 \mathrm{Abc}$ & $+3,56$ & $662 \pm 0,83 \mathrm{Aab}$ & $-2,07$ \\
\hline Imazethapyr & $1 / 2 R$ & $640 \pm 1,25 \mathrm{Abc}$ & $+3,56$ & $640 \pm 0,77 \mathrm{Aab}$ & $-5,32$ \\
\hline Sulfentrazone & $1 / 2 R$ & $614 \pm 0,68 \mathrm{Abcd}$ & $-0,65$ & $632 \pm 0,48 \mathrm{Ab}$ & $-6,51$ \\
\hline Fenoxaprop & $1 / 2 R$ & $566 \pm 1,01 \mathrm{Bcd}$ & $-8,41$ & $642 \pm 0,63 \mathrm{Aab}$ & $-5,03$ \\
\hline Metribuzin & $1 / 2 \mathrm{R}$ & $532 \pm 1,19 B d$ & $-13,92$ & $618 \pm 1,01 \mathrm{Ab}$ & $-8,58$ \\
\hline $\mathrm{CV}(\%)$ & & 3,18 & & 4,27 & \\
\hline
\end{tabular}

Médias seguidas pela mesma letra maiúscula na linha e minúscula na coluna não diferem significativamente entre si pelo teste de Tukey $(\alpha=5 \%)$

${ }^{1}$ Concentração dos produtos: $\mathrm{R}=$ recomendada, $1 / 2 \mathrm{R}=$ metade da recomendada.

${ }^{2}$ Relação com a testemunha $=[($ Média de UFC $/ \mathrm{mL}$ do tratamento $/$ Média de UFC $/ \mathrm{mL}$ da testemunha $\times 100)-100]$, sendo os valores positivos para aumento de UFC e negativos para a redução. 
Nenhum tratamento diferiu significativamente da respectiva testemunha quanto à redução da média de UFC/mL. Entretanto, fenoxaprop, lactofen, metribuzin, sulfentrazone e imazethapyr, na CR, estimularam a germinação de esporos, após uma hora de incubação, com diferença significativa apenas para fenoxaprop (Tabela 4).

Silva et al. (2006) verificaram resultados semelhantes em testes com fungicidas, com variação no efeito causado em função dos diferentes produtos testados. Além disso, segundo os autores, tal como aqui observado, a maioria dos fungicidas testados foi compatível com esporos de Btk, sendo que apenas fentin hidróxido reduziu a germinação de esporos diferindo significativamente da testemunha.

As maiores médias de UFC/mLforam observadas no tratamento CR, no tempo de um hora de incubação. Além disso, somente fenoxaprop e lactofen, na $\mathrm{CR}$, apresentaram redução significativa na germinação em relação ao tempo de incubação (Tabela 4).

Em testes semelhantes com inseticidas e os produtos comerciais Biotrol XK e Biotrol BTB à base de Bt, CHen et al. (1974) verificaram que carbaril e estirofós diminuíram a viabilidade dos esporos para Biotrol XK, porém esta aumentou com o produto propoxur. Por sua vez, Biotrol BTB foi compatível com todos os produtos testados, indicando que pode haver efeito da formulação ou da variedade de Bt empregada.

Vale ressaltar ainda que os componentes de uma formulação podem também causar algum efeito sobre a germinação de esporos, tal como observaramMoRRIS, (1975) com emulsificantes, e MoINO JunIOR et al. (1995) comparando diferentes tipos de óleo de soja como veículo para uma formulação tipo óleo emulsionável de Btk.

\section{Comparação entre as técnicas de avaliação em- pregadas}

Os testes in vitro referentes aos efeitos dos produtos fitossanitários sobre entomopatógenos têm como vantagem a exposição máxima destes aos produtos. Nestas condições, detectada a inocuidade, a aplicação em campo é garantida. Contudo, a toxicidade in vitro não significa que ela será observada em campo (Alves et al., 1998).

Com relação à técnica de discos impregnados, quando estes entram em contato com a superfície do meio de cultura, a velocidade de absorção de água para o papel é maior que a difusão da substância no meio de cultura (KonemAn et al., 2001). Assim, a concentração do produto adjacente ao disco pode exceder a do próprio disco e, à medida que aumenta a distância em relação ao disco, há uma redução logarítmica da concentração da substância.
Embora nenhum herbicida tenha sido classificado como incompatível, ressalta-se que a avaliação com discos é apenas visual, sem a quantificação do inóculo, sendo necessário complementar com outras técnicas que permitem tal quantificação.

Além disso, não há uma relação entre o tamanho do halo (difusão in vitro) com a atividade antimicrobiana in vivo, mas com a capacidade de difusão do produto. Dessa forma, independente da toxicidade haverá formação de halo de inibição ao redor do disco, que dependerá da capacidade de difusão do produto no meio de cultura (KonEMAM et al., 2001).

A maioria dos tratamentos apresentou halo de inibição com algumas UFC e, segundo KonEMAN et al. (2001), estas podem ser colônias mutantes oriundas de células resistentes ou células de outros microrganismos. Neste caso, provavelmente, a existência de células resistentes ou a difusão irregular do produto no meio de cultura podejustificar a formação dehalos com UFC/ $\mathrm{mL}$, uma vez que se trabalhou com cultura pura de Btk.

Com relação à técnica de mistura dos herbicidas ao meio de cultura antes da solidificação, não houve formação de UFC, sendo classificados como incompatíveis a Btk, diferindo do resultado verificado na técnica com discos.

Tais resultados diferem dos obtidos porSALERNOet al. (1999), quando testaram herbicidas, fungicidas e inseticidas e verificaram que o efeito variou conforme o produto e a concentração utilizada. Entretanto, segundo os autores, fenoxaprop-p-etil permitiu a formação de UFCa 1,6\% da concentração recomendada.

Por meio da mesma técnica, BATISTA FilHo et al. (2001) avaliaram o efeito de inseticidas sobre Bt e observaram que o efeito variou de acordo com o produto econcentração utilizada, sendo que diafentiuron na menor concentração estimulou significativamente a germinação. Por outro lado, com imidacloprida a média de UFC foi maior no tratamento com a maior concentração do produto e para monocrotofós e deltrametrina, na concentração máxima, não houve germinação.

Embora sejam diferentes e apresentaram resultados diferentes quanto aos efeitos dos produtos sobre Btk, ambas as técnicas mencionadas anteriormente são semelhantes quanto à condição de oxigenação. Porém, a técnica na qual se mistura os produtos ao meio de cultura apresenta como vantagem a quantificação do inóculo, a distribuição mais uniforme dos produtos no meio, além de independer da capacidade de difusão destes.

Contudo, na comparação da técnica dos produtos misturados ao meio de cultura e a técnica de incubação em meio líquido, o fator oxigenação pode ser relacionado aos resultados, uma vez que, segundo MorAEs et al. (1980), há a necessidade de uma condi- 
ção ideal de oxigenação, pois tanto a ausência como o excesso de oxigênio inibe o crescimento bacteriano. Vale ressaltar que a difusão do oxigênio em meio líquido sob agitação é maior, o que reforça os resultados aqui obtidos (PINTO, comunicação pessoal).

Resultados semelhantes foram obtidos por IGNATENKO et al. (1983), que observaram maior crescimento bacteriano de acordo com a elevação da oxigenação, e também AvignONE-RossA et al. (1992) verificaram influência da oxigenação sobre a produção de esporos e cristais de Bt.

Além do fator oxigenação, no caso da técnica com os produtos misturados ao meio decultura, as células encontram-se muito próximas umas às outras. Nessa condição, o constante contato com os metabólitos secundários produzidos podeter efeitoinibitório sobre as células. Esse contato de metabólitos na técnica em meio de cultura líquido se dá através do meio, o que reduz o efeito destes sobre as células (PINTO, comunicação pessoal).

Nesse sentido, a avaliação em meio líquido é a mais confiável, pois possibilita a dispersão dos metabólitos secundários, garante constante oxigenação, e total distribuição do produto no meio de cultura. Isto associado ao constante contato do microrganismo com o substrato aumenta a possibilidade de metabolização dos componentes do meio e conseqüente crescimento populacional.

Silva; Neves (2005) também verificaram variação entre técnicas, concentrações e produtos utilizados em trabalho com fungos entomopatogênicos, e os resultados obtidos pelos autores, juntamente com os obtidos neste trabalho, chamam a atenção para a adequabilidade das técnicas empregadas na avaliação do efeito de produtos fitossanitários sobre microrganismos entomopatogênicos, para que se possa atestar com segurança a toxicidade de tais produtos.

Ainda, ressalta-se que, no presente trabalho, foram utilizados produtos fitossanitários comerciais, não se considerand o o efeito dos componentes desses produtos de maneira isolada. Assim, estudos mais detalhados sobre a metabolização destes componentes, bem como estudos de campo e semi-campo,juntamente com cristais são necessários para a confirmação da eficiência dessa estratégia.

\section{CONCLUSÕES}

O efeito dos herbicidasvaria conformea técnica de avaliação empregada, o estágio/ fase do ciclo de vida do patógeno (célula e esporo), e as concentrações dos produtos.

A técnica de avaliação em meio líquido demonstrou ser a mais confiável para testar o efeito de herbicidas sobre células de Btk.
OBtk tem a capacidade de metabolizar sulfetrazone e imazethapyr.

Não ocorreu efeito negativo dos herbicidas sobre a germinação dos esporos, porém ocorreu redução da germinação com maior tempo de contato.

\section{REFERÊNCIAS}

ALVES, S.B.; MOINO JÚNIOR, A.; ALMEIDA, J.E.M Produtos fitossanitários e entomopatógenos. In: Alves, S.B. (Ed.). Controle Microbiano de Insetos. 2. ed. Piracicaba: FEALQ, 1998. cap. 8, p.217-238.

AVIGNONE-ROSSA, C.; ARCAS, J.; MIGNONE, C. Bacillus thuringiensis growth, sporulation and $\alpha$ endotoxin production in oxygen limited and nonlimeted cultures. World Journal of Microbiology and Biotechnology, v.8, n.3, p.301-304, 1992.

BATISTA FILHO, A.; ALMEIDA, J.E.M.; LAMAS, C. Effect of Thiamethoxam on Entomopathogenic Microrganisms. Neotropical Entomology, v.30, n.3, p.437-447, 2001.

CHEN, K.; FUNKE, B.R.; SCHULZ, J.T.; CARLSON, R.B.; PROSHOLD, F.I. Effects of certain organophosphate and carbamate inseticides on Bacillus thuringiensis. Journal of Economic Entomology, v.67, n.4, p.471-473, 1974.

DOUGHERTY, E.M.; REICHELDERFER, C.F.; FAUST, R.M. Sensitivity of Bacillus thuringiensis var. thuringiensis to various insecticides and herbicides. Journal of Invertebrate Pathology, v.17, n.2, p.292-293, 1971.

FERREIRA, D.F. Sistema Sisvar para análises estatísticas. Disponível em: <http://www.dex.ufla.br/ danielff/dff02.htm>. Acesso em: 23 dez. 2005.

IGNATENKO, YU.N.; SAKHAROVA, Z.V.; KHOVRYCHEV, M.P.; SHEVTSOV, V.V. Efect of temperature and aeration on growth and spore formation in Bacillus thuringiensis. Microbiology, v.52.n.5, p.553-556, 1983.

JIMENEZ, J.; ACOSTA, N.; FERNANDEZ, R. Efecto de insecticidas y fungicidas sobre la actividade biologica de preparaciones de Bacillus thuringiensis. Protección de Plantas, v.12, n.1, p.45-59, 1989.

KONEMAN, E.W.; ALLEN, S.D.; JANDE, W.M.; SHERECKENBUGER,P.C.; JRWINN, W.C. Provas de Sensibilidade a Agentes Antimicrobianos. In: Diagnóstico microbilógico. Rio de Janeiro: Medici, 2001. 1465p. Cap.15.

MOINO JUNIOR, A.; ALVES, L.F.A.; ALVES, S.B. Compatibilidade do óleo de soja com Bacillus thuringiensis var. kurstaki, Metarhizium anisopliae e Beauveria bassiana. In: CONGRESSO BRASILEIRO DE ENTOMOLOGIA, 15., 1995, Caxambu. Resumos, Caxambu, 1995. 
MORAES, I.O.; SANTANA, M.H.A.; HOKKA, C.O. The influence of oxygen concentration on microbial insecticide production. London: Bergman Press, 1980. p.75-79.

MORAES, I.O.; CAPALBO, D.M.F.; ARRUDA, R.O.M Produção de bactérias entomopatogênicas In: ALVES, S.B. (Ed.) Controle Microbiano de Insetos, Piracicaba: FEALQ, 1998. cap. 26, p.815-843.

MORRIS, O.N. Effect of some chemical insecticides on the germination and repelication of commercial Bacillus thuringiensis. Journal of Invertebrate Pathology, v.26, n.2. p.199-204, 1975.

POLANCZYK, R.A. Estudos de Bacillus thuringiensis Berliner visando ao controle de Spodoptera frugiperda (J.E. Smith). 2004. $144 \mathrm{f}$. Tese (Doutorado em Entomologia) Escola Superior de Agricultura "Luiz de Queiroz" Universidade de São Paulo, Piracicaba, 2004. Disponível em: <http:// teses.usp.br>. Acesso em: 18 nov. 2005.

SALERNO, C.; DIAS, S.; SAGARDOY, M. Efecto de pesticidas sobre cepas de Bacillus thuringiensis bajo condiciones controladas. Revista Argentina de Microbiologia, v.31, p.58-64, 1999.

SILVA R.Z. da; NEVES, P.M.O.J. Techniques and parameters used in compatibility tests between Beauveria bassiana (Bals) Vuill and in vitro phytosanitary products. Pest Management Science, v.61, p.667-674, 2005.
SILVA, E.R.L.; ALVES, L.F.A.; SENE, L; SANTOS, J. BONINI, A.K., POTRICH, M.; NEVES, P.M.O.J. Técnicas para avaliação do efeito "in vitro" de fungicidas sobre Bacillus thuringiensis var. kurstaki. Arquivos do Instituto Biológico, São Paulo, v.73, n.4, p.429-437, 2006.

SOSA-GOMES, D.R.; MOSCARDI, F. Importância das interações entre agroquímicos e entomopatógenos em programas de MIP. In: SIMPÓSIO DE CONTROLE BIOLÓGICO, 8., 2003, São Pedro, SP. Resumos. São Pedro: 2003. p.59.

SUTTER, G.R.; ABRAHANSON, M.D.; HAMILTON, E.W.; VICK, I.D. Compatibility of Bacillus thuringiensis var. Kurstaki and Chemical inseticides. 1. Effect of Insecticide Doses on Bacterial Replication Rate. Journal of Economic Entomology, v.64, n.6, p.13481350, 1971.

VALADARES-INGLIS, M.C.C.; SHILER, W.; SOUZA, M.T. de Engenharia genética de microrganismos agentes de controle biológico. In: MELO, I.S.; AZEVEDO, J.L. (Ed.). Controle Biológico. Jaguariúna: Embrapa Meio Ambiente, 1998. cap.7, p.201-230.

Recebido em $12 / 2 / 07$

Aceito em 7/12/07 